\title{
Infant memory for place information
}

\author{
HARLENE HAYNE, CAROLYN ROVEE-COLLIER, and MARGARET A. BORZA \\ Rutgers University, New Brunswick, New Jersey
}

\begin{abstract}
The present studies were designed to examine the role of place cues in memory retrieval during early infancy. Three-month-old infants were trained to move a mobile by kicking. Two weeks later, memory retrieval was disrupted if they were reminded in a location or place different from where they had been trained, but not if they were reminded in the same place (Experiment 1A). The same result was obtained even though highly salient cues in their immediate visual surround remained unchanged during reminding (Experiments $1 B$ and $1 C$ ). No disruption was seen, however, when retrieval was cued in a different place after only 1 day (Experiment 2). These findings unequivocally demonstrate that infants as young as 3 months encode incidental information about the place where an event occurs and suggest that early memories are buffered against retrieval in potentially inappropriate contexts over the long term.
\end{abstract}

Most theories of human memory propose that information about the place where an event occurs is represented in the memory of that event and is critical in its subsequent retrieval (e.g., Ackerman, 1987; Anderson \& Bower, 1972; Estes, 1973; Medin \& Reynolds, 1985; Medin \& Schaffer, 1978; Raaijmakers \& Shiffrin, 1981; Tulving, 1983). Evidence for this view has been drawn from studies in which adults exhibit poorer retention when trained and tested in different places than when trained and tested in the same place. Godden and Baddeley (1975), for example, reported that divers who learned a list of words underwater exhibited better recall when tested underwater than when on dry land, and vice versa. Likewise, Smith, Glenberg, and Bjork (1978) found that students trained in either a university classroom or the animal colony room remembered better when tested in the same room than when tested in the other room. Similar findings have also been reported in studies with adult animals (e.g., Gordon, 1981; Richardson \& Riccio, 1986; Wittrup \& Gordon, 1982). The importance of contextual cues for memory retrieval in both human and nonhuman adults led Campbell and Spear (1972) to propose that naturally occurring changes in context, either real or perceived, might be a major contributor to the inability of individuals to remember events that occurred during early life-a phenomenon known as "infantile amnesia."

Skepticism about this account, however, has arisen from three different lines of research. First, Fernandez and Glenberg (1985) reported a series of failures to replicate the classic finding that changes in the environmental context at the time of testing affect retention. Their results supported Crowder's assertion that context effects in hu-

This research was supported by Grant MH 32307 from the National Institute of Mental Health to C.R.C. Experiment 1A was presented at the meeting of the Society for Research in Child Development, Toronto, April 1985. Address correspondence and requests for reprints to Carolyn Rovee-Collier, Department of Psychology, Busch Campus, Rutgers University, New Brunswick, NJ 08903. man adults occur only when "sledgehammer" manipulations of context are used: "without such radical interventions, contextual drift is more an article of faith than it is an operational concept" (Crowder, 1985, p. 33). Second, Riccio, Richardson, and Ebner (1984) reviewed evidence of context effects in animals and humans and concluded that contextual cues were so rapidly forgotten that any disruption in retention due to contextual change would be most apparent closest in time to training. Their conclusion effectively negated all accounts of infantile amnesia based on contextual change after relatively long intervals, such as those envisioned by Campbell and Spear (1972). Finally, studies of nonhuman primates (Bachvalier \& Mishkin, 1984), rats (Nadel \& Zola-Morgan, 1984), and amnesic patients (Schacter \& Moscovitch, 1984) led neuropsychologists to conclude that the delayed maturation of the hippocampal formation precludes the encoding and storage of place information early in development (Jacobs \& Nadel, 1985; Nadel, Willner, \& Kurz, 1985; Nadel \& Zola-Morgan, 1984; Schacter \& Moscovitch, 1984). In human infants, the hippocampus is presumably not functional until the 8th or 9th postnatal month. If younger infants are incapable of encoding elements of the context in the first place, they could not possibly be affected by a contextual change, especially after a long interval.

Recent data collected with both animal (Richardson, Riccio, \& McKenney, 1988) and human (Borovsky \& Rovee-Collier, 1990; Butler \& Rovee-Collier, 1989; Rovee-Collier, Griesler, \& Earley, 1985; Rovee-Collier \& Shyi, in press) infants, however, have revealed that changes in the training context do disrupt memory retrieval. In all of the studies with human infants, subjects were trained to produce movement (the reinforcement) in a particular crib mobile (the nominal cue or stimulus) by footkicking. The training context was created by draping a colorful, patterned cloth liner over the sides of the infant's crib or playpen for the duration of each session. At 3 months of age, infants exhibited excellent retention in an altered context after a delay of only 1 day but no 
retention whatsoever when the context was changed after intervals of 3 days and longer (Butler \& Rovee-Collier, 1989; Rovee-Collier, Griesler, \& Earley, 1985). At 6 months of age, infants failed to respond after any retention interval when the liner was altered during the test (Borovsky \& Rovee-Collier, 1990). Most infants fixated the mobile throughout training and testing and appeared not to notice the liner. Yet, when it was changed during testing, they simply stared "blankly" ' at the original mobile without responding, not recognizing it out of context.

At 3 months of age, infants remember the mobile (i.e., respond significantly above baseline during testing) for only 6 to 8 days. Their retention can be restored after longer delays, however, if they are briefly exposed to a reminder (the original training mobile being removed noncontingently by the experimenter) $24 \mathrm{~h}$ prior to the longterm retention test. This reminder procedure, otherwise known as a "reactivation treatment," was modeled after procedures originally developed with infant animals (Campbell \& Jaynes, 1966; Spear \& Parsons, 1976) and is highly effective in alleviating forgetting after retention intervals as long as 4 weeks (Rovee-Collier, Sullivan, Enright, Lucas, \& Fagen, 1980; Sullivan, 1982). The reminder is merely a retrieval cue that is presented in advance of the long-term retention test (a prior-cuing procedure: Spear, 1973). It presumably primes or reactivates the latent memory, increasing its accessibility during the ensuing test. To be effective, a reminder must reinstate the original encoding context fairly precisely (see also Tulving \& Thomson, 1973). If, for example, more than one novel object is substituted into a five-object mobile, it is no more effective than no reminder at all (RoveeCollier, Patterson, \& Hayne, 1985). Even when the original training mobile is used as the reminder, however, changes in the liner at the time of the reactivation treatment impair retrieval of the training memory (Amabile, 1990; Borovsky \& Rovee-Collier, 1990; Butler \& RoveeCollier, 1989).

Although the crib liner in the studies described above created an extrinsic context or setting that was incidental to the response-reinforcement contingency, that is, it neither directly nor indirectly influenced the requirements or demands of the focal task (Baddeley, 1982; Wickens, 1987), this contextual manipulation seems quite different from manipulations used in studies with adults that change the physical location or place in which an event occurred. The present studies were designed, therefore, to determine whether altering the physical location or place where training occurred produces a retention deficit in 3-month-olds analogous to that found in studies of room shifts with adults and previously observed in studies with infants by altering the crib liner. If so, this would challenge the prevailing view that place information is not represented in infant memory prior to 8 or 9 months of age and would provide support for the proposition that contextual changes over the long term might contribute to infantile amnesia (Campbell \& Spear, 1972).

\section{EXPERIMENT 1A}

Butler and Rovee-Collier (1989) reported that changes in context were particularly disruptive of retention at 3 months of age after longer retention intervals. They found, for example, that the effectiveness of a reminder in alleviating forgetting 2 weeks after training was significantly impaired if the reminder was exposed in the presence of a crib liner different from that used when infants had originally been trained. In the present study, therefore, we repeated their procedures but defined the training, reminding, and testing contexts in terms of places in the infant's home that were the same as or different from the place where the infant was originally trained.

\section{Method}

Subjects. Twenty-four infants (12 males, 12 females) were recruited from birth announcements in local newspapers and by word of mouth. The infants ranged in age from 80 to 121 days $(M=$ 90.7 days, $S D=9.1$ ) at the outset of the training. They were randomly assigned to three reactivation groups and a control group $(n=6)$ as they became available for testing. To be included in the final sample, an infant was required to respond at a rate equal to or greater than 1.5 times the baseline rate in 2 of any 3 consecutive minutes of a reinforcement phase during training. Two infants failed to meet this learning criterion. Additional infants were eliminated from the final sample for crying in excess of 2 consecutive minutes in any session $(n=4)$, failing to fixate the mobile for 2 consecutive minutes $(n=5)$, failing to maintain a supine position $(n=$ $1)$, illness $(n=1)$, or a scheduling conflict $(n=2)$. This loss rate is similar to that reported in other studies with infants of this age when multiple sessions were used (e.g., Butler \& Rovee-Collier, 1989; Greco, Hayne, Rovee-Collier, 1990; Hayne, Rovee-Collier, \& Perris, 1987).

Apparatus. One of two mobiles, counterbalanced within groups, served as the reinforcer. Each was composed of five highly detailed, brightly painted wooden figures suspended from the ends and middle of a plastic cross bar (Nursery Plastics, Models 801 and 809).

During all sessions, the mobile was hung from an L-shaped metal stand (BRS, South Plainfield, NJ) that was clamped to the crib siderail closest to the experimenter. A second mobile stand was clamped directly opposite the first, so that the ends of the two suspension bars protruded over the infant's upper abdomen. One end of a white satin ribbon was secured to the infant's ankle, and the other end was connected either to the end of the bar from which the mobile was suspended or to the empty bar, depending upon the training/testing phase.

Procedure. All sessions were in the infants' homes at a time which each mother defined as an alert/play period. Although this time varied among infants, it remained relatively constant across sessions for a given infant.

Training took place during two identical 15 -min sessions that were separated by $24 \mathrm{~h}$. The test session was procedurally identical to the training sessions and occurred 14 days later.

Each session began with a 3-min nonreinforcement period, during which the mobile was hung from one stand and the ankle ribbon was connected to the other. In this arrangement, the mobile was in view, but kicks could not move it. This was followed by a 9-min reinforcement period (acquisition), during which the ankle ribbon was attached to the same stand as the mobile. In this arrangement, each movement of the foot produced a proportional movement of the overhead mobile ("conjugate reinforcement"). At 3 months, infants typically acquire this response-reinforcement contingency within 3-6 min (Rovee \& Rovee, 1969). Finally, each 
session ended with another 3-min nonreinforcement period. The 3-min nonreinforcement period at the outset of Session 1 defined the baseline phase, during which each infant's pretraining operant level was assessed. The final 3 -min nonreinforcement period at the end of Session 2 defined the immediate retention test and provided the standard against which performance during the 3-min nonreinforcement period at the outset of Session 3, the long-term retention test, was compared.

An experimenter, positioned out of the infant's line of sight, recorded kicks per minute of the foot to which the ankle ribbon was secured. A kick was defined as a horizontal or vertical excursion of the foot that at least partially retraced its original path in a smooth, continuous motion (Rovee \& Rovee, 1969).

The reactivation treatment consisted of a brief exposure to the original training mobile (the reminder) moving noncontingently 13 days after the second training session-a delay after which forgetting is complete at this age (Butler \& Rovee-Collier, 1989; Fagen \& Rovee-Collier, 1983; Sullivan, Rovee-Collier, \& Tynes, 1979). During this procedure, the infant was placed in a sling seat in the specified location in front of a mobile suspended from a modified floor microphone stand. One end of a ribbon was attached to the same hook as the mobile; the other was drawn and released for $3 \mathrm{~min}$ by the experimenter, squatting out of sight, at the same rate that the infant had kicked in each of the last $3 \mathrm{~min}$ of acquisition in Session 2 . When the $3 \mathrm{~min}$ elapsed, the mobile was removed from the stand and the mother lifted the infant out of the seat. Twenty-four hours after the reactivation treatment (i.e., 14 days after the conclusion of the second training session), all infants were tested with the original mobile in the place where they had been trained.

The three reactivation groups differed only in terms of the place where the reminder was presented. Each infant in one group received the reactivation treatment in the crib where he/she had been trained; each infant in the second group received the reactivation treatment in his/her bedroom but not in his/her crib; and each infant in the third group received the reactivation treatment in his/her kitchen. To ensure that forgetting had occurred in the absence of any reactivation treatment, a control group was identically trained and tested but received no exposure to the mobile prior to the 14-day long-term retention test.

\section{Results}

Training analyses. A one-way analysis of variance (ANOVA) over the mean kicks per minute during the initial 3-min baseline period in Session 1 indicated that the groups did not differ in operant level. Recall that an infant was required to respond at a rate equal to or greater than 1.5 times the baseline kick rate in 2 of any 3 con- secutive minutes of acquisition in order to meet the learning criterion and be included in the final sample. A oneway ANOVA over the mean kicks per minute during the immediate retention test at the conclusion of training indicated that the final level of acquisition of the groups also did not differ. These analyses ensured that subsequent differences during the long-term retention test could not be attributed to group differences in initial activity or learning prior to the introduction of the experimental manipulation. The learning curves, collapsed across test groups, are presented in Figure 1.

Retention analyses. Retention was evaluated in terms of two standard measures of relative response that have been used in all of our previous studies of infant longterm retention using the mobile paradigm (for review, see Rovee-Collier \& Hayne, 1987). For each infant, a retention ratio was calculated by dividing the infant's mean kick rate during the 3-min long-term retention test at the outset of Session 3 (test session) by the same infant's mean kick rate during the 3-min immediate retention test at the end of Session 2. The resulting ratio indicates the proportion of the infant's performance after zero delay, when retention should be best, that is expressed during the longterm retention test. A retention ratio greater than or equal to 1.00 indicates perfect retention; the lower the retention ratio, the poorer the retention. A group mean retention ratio significantly less than a hypothetical population mean retention ratio of 1.00 (no forgetting) indicates that significant forgetting has occurred.

Because infants have different initial operant levels, however, the absolute value of a mean retention ratio significantly less than 1.00 is not informative as to whether a group's forgetting is partial or complete. To answer this, it is necessary to compute a second relative measure based on each infant's initial baseline response rate, the baseline ratio. This ratio is calculated by dividing each infant's mean kick rate during the 3-min long-term retention test at the outset of Session 3 by his/her mean kick rate during the 3-min baseline phase at the outset of Session 1 (operant level). The baseline ratio expresses the extent to which each infant's mean kick rate during the long-term retention test exceeds his/her pretraining rate. A baseline ra-

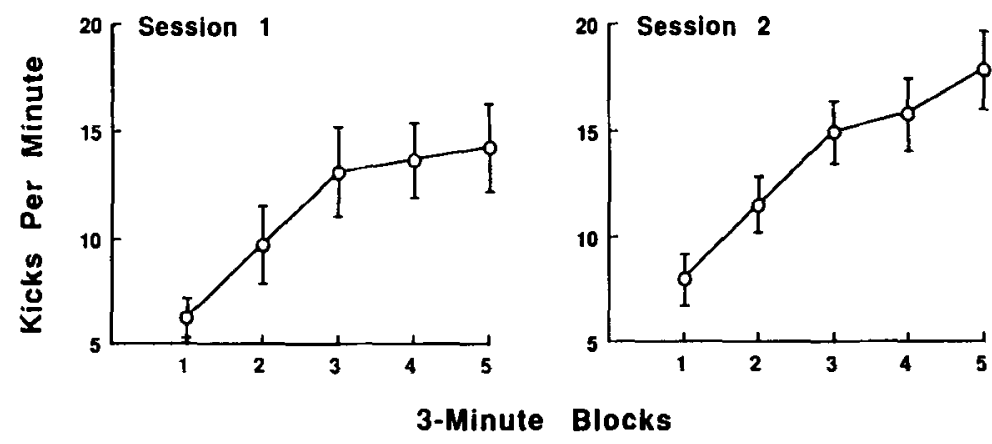

Figure 1. Average learning curves of infants in Experiment 1A, who were trained for two daily 15-min sessions separated by $24 \mathrm{~h}$. The frst and last 3-min block of each session was a nonreinforcement period. 


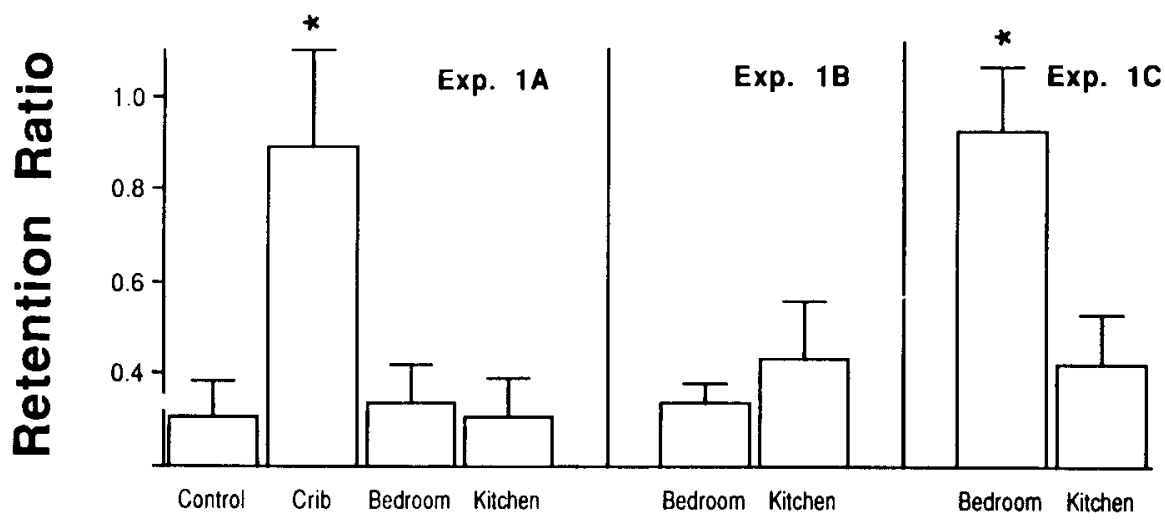

\section{Reminder Context}

Figure 2. Left panel: Mean retention ratios of groups receiving a 3-min reactivation treatment with the original mobile 13 days following the conclusion of training. The reactivation treatment was administered in the crib where training occurred, in the bedroom but not in the crib, or in the kitchen. The control group received no reactivation treatment. All groups were tested in the crib in the bedroom 14 days after the conclusion of training (Experiment 1A). Center panel: Mean retention ratios of groups receiving a 3-min reactivation treatment in a liner-draped portacrib placed either in the bedroom or in the kitchen. Both groups were trained and tested in the bedroom in the liner-draped crib (Experiment 1B). Right panel: Mean retention ratios of groups receiving a 3-min reactivation treatment in a liner-draped portacrib placed in the bedroom or in the kitchen. Both groups were trained and tested in the bedroom in the liner-draped portacrib (Experiment 1C). An asterisk indicates that a group exhibited significant retention ( $M$ baseline ratio signifncantly $>1.00)$. Vertical bars indicate $\pm 1 S E$.

tio of 1.00 indicates that test performance is not above operant level (no retention); a group mean baseline ratio significantly greater than a hypothetical baseline ratio of 1.00 indicates that the group exhibited significant retention.

Independent $t$ tests comparing each group's mean baseline ratio with a hypothetical population mean baseline ratio of 1.00 revealed that infants whose reminder was presented in the crib in which they had been trained exhibited excellent retention during the 14-day test. Their mean baseline ratio was significantly greater than 1.00 $[t(5)=3.73, p<.05]$, and their mean retention ratio was not significantly less than a hypothetical population mean retention ratio of 1.00 . In contrast, infants whose reminder was presented in locations other than where they were trained and infants who received no reminder at all exhibited no retention whatsoever: None of the baseline ratios of these other groups significantly exceeded 1.00 , and all of their retention ratios were significantly less than 1.00 [bedroom-react, $t(5)=8.25, p<.0005$; kitchenreact, $t(5)=8.62, p<.0005$; no-react control, $t(5)=$ $9.20, p<.0005]$.

The mean retention ratios of each group are shown in the left panel of Figure 2. A one-way ANOVA over these ratios yielded a significant main effect of group $[F(3,20)$ $=5.34, p<.007]$. A Tukey's studentized range test indicated that the mean retention ratio of infants who were reminded in the crib where they had been trained was significantly greater than the mean retention ratios of any other group, which did not differ from one another.

\section{EXPERIMENT 1B}

Initially, we had identified the training place as the room in which infants had learned the task and had predicted that a change in place from the bedroom to the kitchen would impair retention the most. The finding that a reactivation treatment when presented in the bedroom but not in the crib was as ineffective as when it was presented in the kitchen suggested that, from the infants' perspective, the training place might be more specific than we had originally suspected; that is, infants appeared to define the training place in terms of their own cribs. From this perspective, failure to reinstate that aspect of the context at the time of the reactivation procedure would have precluded retrieval of the training memory. Alternatively, memory retrieval may not have been impaired by reminding infants outside of their own cribs but by the change in their immediate visual surround (e.g., the absence of the wooden slats on the sides of the crib) during the reactivation procedure. In either instance, however, the failure of the reminder to alleviate forgetting in Experiment $1 \mathrm{~A}$ would have resulted from a contextual change that did not involve remote room cues.

To assess these possibilities, in Experiment 1B we trained, reminded, and tested all infants in the presence of a colorful, patterned cloth liner that was draped over the sides and end of the crib. The liner created a distinctive immediate visual surround that was constant in all sessions (see also Butler \& Rovee-Collier, 1989). One group received the reactivation treatment in a liner-draped 
portacrib that was placed in the same spot in the bedroom where the liner-draped crib had stood during training; the other group received the reactivation treatment in a linerdraped portacrib in the kitchen. Both groups were tested in the liner-draped crib in the bedroom in which they had been trained. Thus, for one group, only the crib was changed at the time of the reactivation treatment, and for the other, both the crib and the room were changed. Yet for both, the immediate visual surround during training, reminding, and testing was constant.

\section{Method}

Subjects. Ten infants ( 5 males, 5 females) were recruited as before and randomly assigned to one of two groups $(n=5)$. The infants ranged in age from 85 to 112 days $(M=91.5$ days, $S D=$ 7.6) at the outset of training. Additional infants were eliminated from the final sample for crying in excess of 2 consecutive minutes in any session $(n=2)$ or because of a scheduling conflict $(n=1)$.

Apparatus. The apparatus was identical to that used in Experiment $1 \mathrm{~A}$ except that during training and testing, the end and sides of the infant's crib were draped with one of two distinctive cloth liners that differed in color and pattern. These were counterbalanced within groups as nearly as possible. Each liner consisted of two $122 \times 114 \mathrm{~cm}$ broadcloth side panels and a $66 \times 122 \mathrm{~cm}$ end panel. One was constructed of green felt squares in a grid pattern $\left(5.08 \mathrm{~cm}^{2}\right.$ separated by $5.08 \mathrm{~cm}$ ) on a bright yellow background. The other was constructed of blue felt stripes $(2.54 \mathrm{~cm}$ wide separated by a $3.18 \mathrm{~cm}$ ) on a bright red background. During the reactivation treatment, each infant was placed inside a portacrib that was draped with the same cloth liner that had been present during training.

Procedure. The training, reminding, and testing procedures were identical to those used before. Thirteen days following the second training session, one group received a 3-min reactivation treatment in a liner-draped portacrib in the bedroom in the spot where the crib had stood at the time of training, and the other group received a 3-min reactivation treatment in a liner-draped portacrib in the kitchen. As before, both groups were tested $24 \mathrm{~h}$ after the reactivation treatment in their own liner-draped cribs in their bedrooms.

\section{Results}

Training analyses. As before, separate one-way ANOVAs were performed over the mean kicks per minute during the baseline and immediate retention test phases. These analyses indicated that the reactivation groups again did not differ either prior to or immediately following training.

Retention analyses. Surprisingly, despite the fact that the original mobile was exposed in the presence of the original, highly distinctive liner during the reactivation treatment, neither group exhibited retention during the 14-day test (see Figure 2, center panel). Their mean baseline ratios were not significantly greater than a theoretical baseline ratio of 1.00 , and their mean retention ratios were significantly less than a theoretical retention ratio of 1.00 [react-bedroom, $t(4)=16.50, p<.0001$; reactkitchen, $t(4)=4.38, p<.01]$. Not surprisingly, a $t$ test revealed that there was no group difference in the retention ratios of the two test groups. Thus, even when the distinctive immediate visual surround was unchanged during training, the reactivation treatment, and testing, memory retrieval was still disrupted when an infant was reminded outside of the crib in which he/she had been trained.

\section{EXPERIMENT 1C}

The results of Experiments $1 \mathrm{~A}$ and $1 \mathrm{~B}$ demonstrated that the effectiveness of an otherwise effective retrieval cue was impaired if it was presented in a context in which only a single element (the crib) was changed. Because a reactivation treatment was ineffective in all instances when it was presented outside of the crib, however, we were unable to determine whether infants had also encoded information regarding the more remote place cues associated with the room in which they had been trained. In Experiment $1 \mathrm{C}$, therefore, we sought to answer this question by training, reminding, and testing infants in the same linerdraped portacrib. Only the room in which the reactivation treatment occurred was changed-from the bedroom to the kitchen.

\section{Method}

Subjects. Ten infants ( 5 males, 5 females) were recruited as before and randomly assigned to one of two groups $(n=5)$. The infants ranged in age from 83 to 115 days $(M=92.9, S D=9.7)$ at the outset of training. Additional infants were eliminated from the final sample because of illness $(n=1)$ or scheduling difficulties $(n=1)$.

Apparatus and Procedure. The apparatus was identical to that used in Experiment 1B. To ensure that differences in retention resulted only from differences in remote place cues and not from differences in the cribs used during reminding or testing, all procedures were administered in the same liner-draped portacrib.

Infants in both groups were trained for two sessions in the linerdraped portacrib in the bedroom. Infants in the control group received a 3-min reactivation treatment 13 days after the conclusion of training in the liner-draped portacrib in the bedroom and were tested 1 day later in the bedroom in the same liner-draped portacrib. Infants in the experimental group received a 3-min reactivation treatment 13 days after the conclusion of training in the same liner-draped portacrib in the kitchen and were tested 1 day later, also in the bedroom, in the same liner-draped portacrib. As in Experiments 1A and 1B, the reactivation procedure consisted of placing the infant in a sling seat inside the portacrib while the experimenter, hidden from view, moved the training mobile noncontingently for $3 \mathrm{~min}$ at the same rate that the infant had kicked in each of the final $3 \mathrm{~min}$ of acquisition in Session 2.

\section{Results}

Training analyses. As before, one-way ANOVAs were performed over the mean kicks per minute during the 3min baseline period at the outset of Session 1 and during the 3-min immediate retention test at the end of Session 2. These analyses again revealed that the groups did not differ either prior to or at the end of training, before the introduction of the room shift.

Retention analyses. As expected, infants reminded in the same room in which training had occurred displayed excellent retention during the 14-day retention test. Their mean baseline ratio was significantly greater than $1.00[t(4)$ $=3.36, p<.01]$, and their mean retention ratio was not significantly less than 1.00 . This result demonstrates that there was nothing peculiar about the portacrib per se: If infants were initially trained in the portacrib, their forgetting was alleviated when a reminder was encountered in that portacrib as long as the room cues were held constant at the time of reminding. 
In contrast, a change in the room cues at the time of the reactivation treatment had a dramatic and deleterious impact on memory retrieval. When the reminder was presented in a room different from that in which training occurred, infants displayed no evidence of retention during the 14-day test. Their mean baseline ratio was not significantly greater than 1.00 , and their mean retention ratio was significantly less than $1.00[t(4)=5.27, p<.005]$ (see Figure 2, right panel). A $t$ test comparing the retention ratios of the two reactivation groups indicated that the mean retention ratio of the group reminded in the kitchen was significantly lower than the mean retention ratio of the group reminded in the bedroom in which they had been trained $[t(8)=2.76, p<.025]$.

\section{Discussion}

Taken together, these results confirm that 3-month-olds, like adults, encode information about the place in which an event occurs. In contrast to findings obtained with adults (Crowder, 1985; Fernandez \& Glenberg, 1985), however, memory retrieval in infancy is highly influenced by seemingly subtle changes in contextual information. In Experiments $1 \mathrm{~A}$ and $1 \mathrm{~B}$, simply removing infants from the crib in which they had been trained precluded retrieval at the time of reminding despite the fact that many other aspects of the original training context (e.g., room cues, crib liner, mobile, experimenter) remained unchanged.

The results of Experiment $1 \mathrm{C}$ further demonstrated that when all aspects of the training context except the room in which the memory was originally encoded were held constant, an otherwise effective reminder (the training mobile) was also ineffective in retrieving the forgotten memory. The latter result is consistent with findings from studies of room shifts with adults (e.g., Smith et al., 1978) and replicates findings previously obtained at both 3 months (Butler \& Rovee-Collier, 1989) and 6 months (Borovsky \& Rovee-Collier, 1990; Rovee-Collier \& Shyi, in press; Shyi, 1990) when the cloth liner that defined the experimental context was changed at the time of reminding. In previous context studies with infants, however, the altered context at the time of reminding was also novel; in the present experiments, the altered reminding context was a highly familiar place in the infant's own home. This indicates that the critical factor underlying the retrieval deficit incurred by an altered context is not its novelty but the fact that it is different; that is, it is not represented in the infant's memory of prior training and therefore is not an adequate source of retrieval cues for that memory.

Reeves and Sperling (1986) advanced an attention-gating model of retrieval from visual short-term memory in which recognition was hypothesized to result from the successful flow of attention through a series of gates, each of which must open and close before attention could pass to the next gate and, ultimately, to the target. Detecting appropriate retrieval cues in the target would access the memory representation, enabling responding. At any point that appropriate retrieval cues were not detected, the next attention gate would not open, and the retrieval process would terminate. Under certain conditions, the partial opening of a gate might allow sufficient attention to flow through it to prevent abortion of the retrieval process. Butler and Rovee-Collier (1989) adapted this model to describe retrieval from longterm memory, proposing that the context within which an event (i.e., making the mobile move) occurs defines the initial attention gate for infants as young as $\mathbf{3}$ months.

Within this theoretical framework, the present data suggest that the perceptual identification of retrieval cues may begin at the most remote or global contextual level. That is, place information that is most remote may define the initial attention gate for memory retrieval early in infancy. The findings from Experiment $1 C$, for example, suggest that if appropriate retrieval cues are not detected at this level, then memory retrieval is not initiated in the first place. If remote place cues that match those in the memory representation are detected, however, then this attention gate opens, and attention flows to the second attention gate-the immediate visual surround. Whether or not cues that match those in the memory representation are detected in the immediate visual surround then determines whether the memory retrieval process continues or terminates (Butler \& Rovee-Collier, 1989).

\section{EXPERIMENT 2}

Riccio et al. (1984) concluded that retention should be most impaired by contextual changes occurring most closely in time to training. Butler and Rovee-Collier (1989, Experiment 1), however, reported that a contextual change was more disruptive after longer than after shorter retention intervals at 3 months. In their experiment, infants were tested in the presence of a different crib liner after various delays following original training. When infants were tested after a 1-day delay, retention was unaffected by the novel context. After retention intervals of 3 days and longer, however, the same contextual change completely eliminated all evidence of retention. Butler and RoveeCollier proposed that fewer contextual cues were required to partially open the attention gate when infants' retention of the specific details of the focal cue (the mobile) was still perfect. As their memory of the details of that cue faded over time, however, more contextual cues had to be detected to sustain the retrieval process.

In Experiment 2, therefore, we asked whether altering room cues during a retention test after a delay of only 1 day, when retention of the newly acquired memory is typically perfect at this age, would have the same effect as altering them during a reactivation procedure after a delay of 13 days, when the newly acquired memory is forgotten. On the basis of the findings of Butler and RoveeCollier (1989), we predicted that it would not. To this end, we trained two groups of infants in a liner-draped portacrib in the bedroom and tested them 1 day later in the same liner-draped portacrib either in the bedroom, where they had been trained, or in the kitchen.

\section{Method}

Subjects. Ten infants ( 5 males, 5 females) were recruited as before and randomly assigned to one of two groups $(n=5)$. The in- 
fants ranged in age from 85 to 114 days $(M=91.2, S D=9.1)$ at the outset of training. An additional infant was eliminated from the final sample for crying in excess of 2 consecutive minutes during training.

Apparatus and Procedure. The apparatus was identical to that used in Experiment 1C. Also as before, all procedures were administered in the same liner-draped portacrib.

Infants in the control group were trained for two sessions in the liner-draped portacrib in the bedroom and were tested 1 day later in the same liner-draped portacrib in the bedroom. Infants in the experimental group were trained for two sessions in the liner-draped portacrib in the bedroom and were tested 1 day later in the same liner-draped portacrib in the kitchen. Thus, there were two procedural differences between this experiment and the previous ones. First, the delay between training and testing was only 1 day rather than 14 days, and second, the shift in room cues occurred at the time of the test (a contemporaneous-cuing procedure; Spear, 1973) rather than at the time of the reactivation treatment (a prior-cuing procedure; Spear, 1973).

\section{Results}

Training analyses. As before, one-way ANOVAs were performed over the mean kicks per minute during the 3min baseline period at the outset of Session 1 and during the 3-min immediate retention test at the end of Session 2. These analyses again revealed that the groups did not differ either prior to or at the end of training, before the introduction of the room shift.

Retention analyses. As expected, infants tested in the bedroom in which training had occurred displayed excellent retention during the 1-day retention test. Their mean baseline ratio was significantly greater than $1.00[t(4)=$ $2.56, p<.05$ ], and their mean retention ratio was not significantly less than 1.00 . This finding is consistent with that obtained when Butler and Rovee-Collier (1989) trained and tested infants in their home cribs in the presence of the same crib liner after the same retention interval.

Unlike the disruptive effect of a room change at the time of the reactivation treatment in Experiment $1 \mathrm{C}$, however, a room change at the time of the 1-day retention test had no impact on memory retrieval. When retrieval was cued in a room (the kitchen) different from the one in which infants had been trained, they displayed excellent retention. Their mean baseline ratio was significantly greater than $1.00[t(4)=3.59, p<.025]$, and their mean retention ratio was not significantly less than 1.00 (see Figure 3 ). The retention ratios of the two test groups did not differ.

\section{Discussion}

Contrary to the conclusion of Riccio et al. (1984), the results of the present experiments indicate that changes in context did not exert their greatest impact closest in time to original training. In the present study, as before (Butler \& Rovee-Collier, 1989), highly salient cues in the mobile apparently overrode conflicting remote place information as a basis for memory retrieval after a relatively short (1-day) delay. When the retention interval was longer, however, a change in the place where learning had originally occurred impaired the effectiveness of the mobile as a retrieval cue. These data suggest that more contextual support is required to cue retrieval once memories have

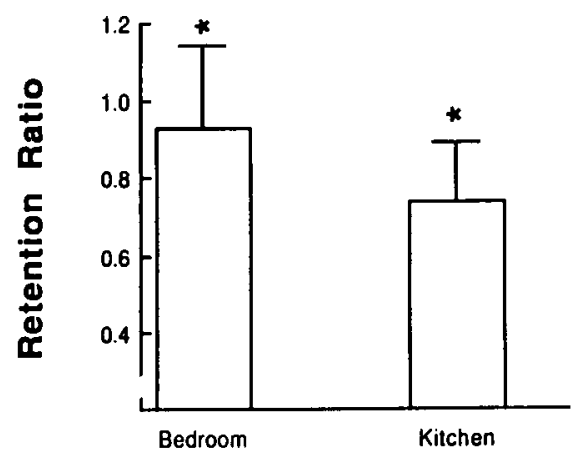

Test Context

Figure 3. Mean retention ratios of two groups trained in the linerdraped portacrib in the bedroom and tested 1 day later in the linerdraped portacrib in either the bedroom or the kitchen. An asterisk indicates that a group exhibited significant retention ( $M$ baseline ratio significantly $>1.00)$. Vertical bars indicate $\pm 1 S E$.

become less accessible. Additional support for the latter conclusion has been obtained at both 3 months (Greco, Hayne, \& Rovee-Collier, 1987; Hayne, 1990) and 6 months (Borovsky \& Rovee-Collier, 1990; Rovee-Collier \& Shyi, in press).

\section{GENERAL DISCUSSION}

Nadel and his colleagues have asserted that "virtually all learning during infancy is ... independent of context" (Nadel et al., 1985, p. 398; see also Nadel \& ZolaMorgan, 1984). Despite a lack of empirical support, the notion that early memory is context-free has become part of the conventional wisdom of psychology (Schacter \& Moscovitch, 1984). The inability of adults to remember events from their infancy and early childhood, for example, has been attributed to a lack of contextual content in those memories. Thus adults, who frequently organize and retrieve memories on the basis of where an event occurred, are unable to retrieve memories that lack this episodic organization (e.g., Jacobs \& Nadel, 1985; Mandler, 1984; Nelson, 1984).

The present findings unequivocally demonstrate that infants' early memories, like those of adults, are not contextindependent. Instead, the retrieval of infants' memories weeks later depends critically on the environmental information that was encoded in the original memory representation. Rather than being impervious to the effects of context, early memories, after long delays, appear to be highly buffered from the possibility of retrieval in potentially inappropriate contexts, where they might be unadaptive or modified. To the extent that subtle changes in place information are not reliably demonstrated in studies with adults (Crowder, 1985; Fernandez \& Glenberg, 1985), we conclude that the encoding of information about the place where events occur may be even more important for memory retrieval in infancy than it is at older ages. Because the place information in our studies derived from 
the familiar context of the infants' own homes, we believe that young infants not only encode contextual information associated with explicit experimental events but also that they do so normally in association with the stream of events that occur over the course of their day-to-day interactions.

The latter suggestion is consistent with the proposal of Hasher and Zacks (1979) that information about the time, spatial location, and frequency of an event is automatically encoded. Evidence that memory performance for frequencyof-occurrence information appeared to be age-invariant led them to propose that humans are biologically or genetically prepared to process automatically temporal, place, and frequency information about a wide variety of naturally occurring events. Their only requirement for automatically encoded attributes to enter long-term memory was that the subject must attend to the information either incidentally or intentionally, irrespective of the other resources available to the subject for processing information at the time. Subsequent research on automatic versus effortful processing has focused primarily on the encoding of frequency information (for review, see Hasher \& Zacks, 1984; Hasher, Zacks, Rose, \& Sanft, 1987). The present data from infants suggest that the encoding of place information is also age-invariant and occurs under conditions that can only be considered truly incidental.

The findings of the preceding studies are also consistent with the proposal that long-term changes in context may contribute significantly to the forgetting of infantile memories (Campbell \& Spear, 1972). Given that very early memories are so intimately tied to the context in which they were established, infantile amnesia could result, at least in part, from retrieval failures associated with either real or perceived changes in context (see also Gordon, 1981; Perkins, 1965; Rovee-Collier, Griesler, \& Earley, 1985). The present finding that a contextual change is particularly disruptive after a long retention interval suggests that retrieval of a particular memory may be permanently disrupted by changes that occur in the encoding context over the long term. From this perspective, the principles that describe infantile amnesia would not be qualitatively different from the principles that describe other instances of spontaneous forgetting (Tulving, 1983; Tulving \& Thomson, 1973).

Finally, the present data have implications for our current understanding of the neuropsychological basis of memory development. Many studies have shown that hippocampal damage results in an inability to perform tasks that require the use of place information. This finding has been obtained repeatedly in studies using both human (for review, see Nadel \& Zola-Morgan, 1984; Schacter \& Moscovitch, 1984; Squire, 1987) and animal (for review, see O'Keefe \& Nadel, 1978) adults. Given the importance of the hippocampus for normal processing of place information in adults, and given that the hippocampus in the human infant is not functional until 8 or 9 months of age and presumably continues to undergo maturational changes during the first 3 years of life (see Jacobs \& Nadel, 1985; Nadel \& Zola-Morgan, 1984; Schacter \& Moscovitch, 1984), the present data indicate that either the hippocampus matures earlier than previously thought or that an alternative structure is responsible for the encoding and maintenance of place information earlier in development. In this regard, the present data suggest an important distinction between information about place and information about the spatial relations between places (e.g., a cognitive map). A mature hippocampus may be required only for the representation or integration of information about spatial relations and not for information about place.

Clearly, by 3 months, memory retrieval over the long term is governed by the contextual variables that define the place in which an event occurred.

\section{REFERENCES}

Ackerman, B. P. (1987). Descriptions: A model of nonstrategic memory development. In H. W. Reese (Ed.), Advances in child development and behavior (Vol. 20, pp. 143-183). New York: Academic Press.

AmABile, T. A. (1990). Contextual variation and memory retrieval by 6-month-olds. Unpublished doctoral dissertation, Seton Hall University, South Orange, NJ

Anderson, J. R., \& Bower, G. H. (1972). Recognition and retrieval processes in free recall. Psychological Review, 79, 97-123.

Bachvalier, J., Mishí, M. (1984). An early and a late developing system for learning and retention in infant monkeys. Behavioral Neuroscience, $98,770-778$.

BAdDeley, A. D. (1982). Domains of recollection, Psychological Review, 89, 708-729.

Boroysky, D., Rover-Collier, C. (1990). Attention-gating of memory retrieval by context at 6 months. Child Development, 61, 1569-1583.

Butler, J., Rovee-Collier, C. (1989). Contextual gating of memory retrieval. Developmental Psychobiology, 22, 533-552.

Campeell, B. A., Jaynes, J. (1966). Reinstatement. Psychological Review, 73, 478-480.

Campbell, B. A., \& Spear, N. E. (1972). Ontogeny of memory. Psychological Review, 79, 215-236.

Crowder, R. L. (1985). Basic theoretical concepts in human leaming and cognition. In L. -G. Nilsson \& T. Archer (Eds.), Perspectives on leaming and memory (pp. 19-37). Hillsdale, NJ: Erlbaum.

Estes, W. K. (1973). Memory and conditioning. In F. J. McGuigan \& D. B. Lumsden (Eds.), Contemporary approaches to conditioning and learning (pp. 265-286). New York: Wiley.

Fagen, J. W., Rovee-Coluer, C. (1983). Memory retrieval: A timelocked process in infancy. Science, 222, 1349-1351.

Fernandez, A., \&lenberG, A. M. (1985). Changing environmental context does not reliably affect memory. Memory \& Cognition, 13, 333-345

Godden, D. R. , \& BADdeley, A. D. (1975). Context-dependent memory in two natural environments: On land and underwater. British Journal of Psychology, 66, 325-332.

Gordon, W. C. (1981). Mechanisms for cue-induced retention enhancement. In N. E. Spear \& R. R. Miller (Eds.), Information processing in animals: Memory mechanisms (pp. 319-339). Hillsdale. NI: Erlbaum.

Greco, C., Hayne, H., Rovee-Coller, C. (1987, April). Conextual determinants of category inclusion. Paper presented at the meeting of the Society for Research in Child Development, Baltimore, MD

Greco, C., Hayne, H., Rovee-Collier, C. (1990). Roles of function, reminding, and variability in categorization by 3-month-old infants. Journal of Experimental Psychology: Human Leaming \& Memory, 16, 617-633.

Hasher, L., \& Zacks, R. T. (1979). Automatic and effortful processes in memory. Journal of Experimental Psychology: General, 108, 356-388

HASHER, L., \& ZACKS, R. T. (1984). Automatic processing of fundamental information: The case of frequency of occurrence. American Psychologist, 39, 1372-1388.

HASher, L., ZACKS, R. T., RoSe, K. C., a SANFT, H. (1987). Truly 
incidental encoding of frequency information. American Journal of Psychology, 100, 69-91.

HAYNE, H. (1990). The effect of multiple reminders on long-term retention in human infants. Developmental Psychobiology, 23, 453-477.

Hayne, H., Rovee-Collier, C., \& Perris, E. E. (1987). Categorization and retrieval by 3-month-olds. Child Development, 58, 750-767.

JACOBS, W. J., NADEL, L. (1985). Stress-induced recovery of fears and phobias. Psychological Review, 92, 512-531.

MANDLER, J. M. (1984). Representation and recall in infancy. In M. Moscovitch (Ed.), Advances in the study of communication and affect: Vol. 9. Infant memory (pp. 75-101). New York: Plenum.

MediN, D. L., \& Reynolds, T. J. (1985). Cue-context interactions in discrimination, categorization, and memory. In P. D. Balsam \& A. Tomie (Eds.), Context and learning (pp. 323-356). Hillsdale, NJ: Erlbaum.

Medin, D. L., \& SCHAFFeR, M. M. (1978). Context theory of classification. Psychological Review, 85, 207-238.

NAdEl, L., Willner, J., \& KuRz, E. M. (1985). Cognitive maps and environmental context. In P. D. Balsam \& A. Tomie (Eds.), Context and learning (pp. 385-406). Hillsdale, NJ: Erlbaum.

NADEL, L., \& Zola-Morgan, S. (1984). Infantile amnesia: A neurobiological perspective. In M. Moscovitch (Ed.), Advances in the study of communication and affect: Vol. 9. Infant memory (pp. 145-172). New York: Plenum.

Nelson, K. (1984). The transition from infant to child memory. In M. Moscovitch (Ed.), Advances in the study of communication and affect: Vol. 9. Infant memory (pp. 103-130). New York: Plenum Press.

O'KeEFE, J., \& NADEL, L. (1978). The hippocampus as a cognitive map. Oxford: Clarendon.

PerkINs, C. C. (1965). A conceptual schema for studies of stimulus generalization. In D. I. Mostofsky (Ed.), Stimulus generalization (pp. 3854). Palo Alto: Stanford University Press.

RaAumakers, J. G., \& Shiffrin, R. M. (1981). Search of associative memory. Psychological Review, 88, 93-134.

REEVES, A., \& SPERLING, G. (1986). Attention gating in short-term visual memory. Psychological Review, 93, 180-206.

Riccio, D. C., Richardson, R., Ebner, D. L. (1984). Memory retrieval deficits based upon altered contextual cues: A paradox. Psychological Bulletin, 96, 152-165.

RichaRDSON, R., Riccio, D. C. (1986). An examination of a contextual component of memory following recovery from anterograde amnesia in rats. Physiological Psychology, 14, 75-81.

Richardson, R., Riccio, D. C., McKenney, M. (1988). Stimulus attributes of reactivated memory: Alleviation of ontogenetic forgetting in rats is context specific. Developmental Psychobiology, 21, 135-143.

RoveE, C. K., \& RoveE, D. T. (1969). Conjugate reinforcement of infant exploratory behavior. Joumal of Experimental Child Psychology, 8, 33-39.

Rovez-Collier, C., Griesler, P. C., Earley, L. A. (1985). Contextual determinants of retrieval in three-month-old infants. Learning \& Motivation, 16, 139-157.
Rovee-Collier, C., \& Hayne, H. (1987). Reactivation of infant memory: Implications for cognitive development. In H. W. Reese (Ed.), Advances in child development and behavior (Vol. 21, pp. 185-238). New York: Academic Press.

Rovee-Collier, C., PATterson, J., \& Hayne, H. (1985). Specificity in the reactivation of infant memory. Developmental Psychobiology, 19, 559-574.

Rovee-Collier, C., \& SHYI, C.-W. G. (in press). A functional and cognitive analysis of infant long-term retention. In C. J. Brainerd, $M$. L. Howe, \& V. F. Reyna (Eds.), The development of long-term memory. New York: Springer-Verlag.

Rovee-Collier, C., Sullivan, M. W., Enright, M., Lucas, D., \& FAGEN, J. W. (1980). Reactivation of infant memory. Science, 208, 1159-1161.

SChaCTER, D. L., \& Moscovitch, M. (1984). Infants, amnesiacs, and dissociable memory systems. In M. Moscovitch (EJ.), Advances in the study of communication and affect: Vol. 9. Infant memory (pp. 173216). New York: Plenum.

Shyi, C.-W. G. (1990, March). The effects of configuration and component information on retrieval at 6 months. Paper presented at the meeting of the Eastern Psychological Association, Philadelphia, PA.

SMITH, S. M., Glenberg, A., \& Bjork, R. A. (1978). Environmental context and human memory. Memory \& Cognition, 6, 342-353.

Spear, N. E. (1973). Retrieval of memories in animals. Psychological Review, 80, 163-194.

SPEAR, N. E., \& PARSONS, P. J. (1976). Analysis of a reactivation treatment: Ontogenetic determinants of alleviated forgetting. In D. L. Medin, W. A. Roberts, \& R. T. Davis (Eds.), Processes of animal memory (pp. 135-165). Hillsdale, NJ: Erlbaum.

SQuiRe, L. R. (1987). Memory and brain. New York: Oxford University Press.

Sullivan, M. W. (1982). Reactivation: Priming forgotten memories in human infants. Child Development, 57, 100-104

Sulluvan, M. W., Rovee-Colluer, C. K., \& Tynes, D. M. (1979). A conditioning analysis of infant long-term memory. Child Development, 50, 152-162.

Tulving, E. (1983). Elements of episodic memory. New York: Oxford University Press.

Tulving, E., \& Thomson, D. M. (1973). Encoding specificity and retrieval processes in episodic memory. Psychological Review, 80, 352-372.

Wickens, D. D. (1987). The dual meanings of context: Implications for research, theory, and applications. In D. S. Gorfein \& R. R. Hoffman (Eds.), Memory and learning (pp. 135-172). Hillsdale, NJ: Erlbaum.

WITTRUP, M., \& GoRDON, W. C. (1982). Alteration of a training memory through cueing. American Journal of Psychology, 95, 497-508.

(Manuscript received April 16, 1990 revision accepted for publication January 25,1991 .) 